\title{
Correspondence
}

\section{ASSOCIATION BETWEEN ALZHEIMER DISEASE AND AMYOTROPHIC LATERAL SCLEROSIS?}

\section{To the Editor:}

I read with interest the recent article by Frecker et al ${ }^{1}$ discussing the possible association between Alzheimer disease (AD) and amyotrophic lateral sclerosis (ALS).

To date, 617 consecutive, unrelated index cases attending the Clinic for Alzheimer Disease and Related Disorders have had detailed family histories taken using the family history method with multiple informants. ${ }^{2}$ Three relatives of 2 out of 233 $(0.86 \%)$ index cases with a diagnosis of "probable" AD according to recognized criteria ${ }^{3}$ possibly had ALS.

Family " $A$ " was of Norweigan ancestry. The index case, the eldest of 2 children, had the onset of her dementia at approximately age 50 . She is still alive at age 55 . Her sister, aged 44 , is alive and well. Her father died at age 66 from a brain tumor and was mentally alert. Her mother died at age 62 and the diagnosis of ALS in this lady was confirmed by autopsy. There was one maternal uncle (brother of the index case's mother) who reportedly suffered from dementia and ALS. An autopsy performed in 1974 confirmed the diagnosis of ALS, but the etiology of the dementia was not resolved.

Family "B" was of English ancestry. The index case, the youngest of four children, had the onset of her dementia at age 72. She is still alive at age 79. One of her brothers died at age 18 during World War II and another brother died at age 75 from heart problems and was mentally alert until his death. Her sister also developed dementia at age 72 and died at age 77 with a neuropathologically confirmed diagnosis of $A D$. The index case's father died at age 86 and was mentally alert until his death. Family informants reported that her mother had a "neurological condition", but all relevant clinical records on this lady have been destroyed. However, clinical records on the index case's sister were obtained. These stated that "her mother died at age 67 , secondary to some neurological disease that sounds similar to ALS".

One hundred forty-six index cases seen at the Clinic are presently diagnosed as "possible" AD. ${ }^{3}$ Of these, informants for one family reported a relative with ALS. Family "C" was of German, Dutch and English ancestry. The index case, the second of four children, had the onset of her dementia at age 62 and is still alive at age 67. Her eldest sister died in her mid-fifties from a brain tumor. Another sister is alive and well at age 65 . Her only brother died at approximately age 60 from ALS, diagnosed clinically but there was no autopsy.

In summary, out of 379 consecutive, unrelated index cases with a diagnosis of "probable" or "possible" AD, 3 (0.79\%) had a total of 4 first- or second-degree relatives reported to have ALS. Assuming a prevalence for ALS of 1 in $100,000,{ }^{4}$ this is more frequent than expected. We therefore agree with Frecker and colleagues' that further investigation is warranted on the possible association between ALS and AD.
This work was supported by the Alzheimer Society of British Columbia.

A.D. Sadovnick

Department of Medical Genetics

U.B.C.

Vancouver, B.C.

1. Frecker MF, Fraser FC, Andermann E, et al. Association between Alzheimer Disease and Amyotrophic Lateral Sclerosis? Can J Neurol Sci 1990; 17: 12-14.

2. Andreasen NC, Edicott J, Spitzer RL. The family history method using diagnostic criteria: reliability and validity. Arch Gen Psychiatry 1977; 34: 1229-1235.

3. McKahnn G, Drachman D, Folstein M, et al. Clinical diagnosis of Alzheimer's disease: report of the NINCDS-ADRDA Work Group under the auspices of the Department of Health and Human Services Task Force on Alzheimer's disease. Neurology 1984; 34: 939-44.

4. Kurtzke KF. Epidemiology of amyotrophic lateral sclerosis. In: Rowland LP, ed. Human Motor Neuron Diseases. New York: Raven Press 1982; 281-302.

\section{POSSIBLE INTERACTIONS BETWEEN DEPRENYL AND PROZAC}

\section{To the Editor:}

Fluoxetine (Prozac) and Selegiline (Deprenyl), are two new medications which have only recently been introduced on the North American market. There is limited experience using these medications in combination, and we would like to describe two patients in which there may have been an interaction between these two drugs.

The first patient is a 46-year-old woman, with moderately severe, left sided Parkinson's disease, who was maintained on Prolopa 15/12.5 every two hours and bromocriptine $10 \mathrm{mg}$ t.i.d. She was also taking amitriptyline $50 \mathrm{mg}$ hs for depression, which over the years had been considered to be an atypical depression. She had taken selegiline for a month in the fall of 1989 , but discontinued it because of lack of perceived benefit.

In January of 1990, because of anticholinergic side-effects, the amitriptyline was discontinued and fluoxetine $20 \mathrm{mg}$ q.a.m. initiated. Selegiline was re-started about ten days later. Initially, the patient felt much better. However the next month, she became increasingly hyperactive, over communicative, elated and creative. Her actions and judgement appeared grossly impaired, and her physicians thought her to be manic. Both the selegiline and fluoxetine were discontinued, and the patient slowly improved, over the next 2 months.

Fluoxetine has previously been reported to cause mania 1,2 although usually at higher doses than $20 \mathrm{mg}$ a day, and manic symptoms resolved quickly with discontinuation of fluoxetine. Selegiline is metabolized to 1 -amphetamine and 1-methamphetamine, and may cause agitation in some patients. In one case, selegiline alone was reported to cause manic behavior. ${ }^{3}$ Thus, the severe prolonged mania seen in this patient may have been due to the concomitant use of selegiline and fluoxetine.

The second patient, a 56-year-old woman, with moderate 